\title{
Comunicação
}

[Communication]

\section{Corpo estranho traqueal em cão}

\author{
[Tracheal foreign body in dog] \\ A.S. Gouvê, J. Aguiar, M. Mucillo, R. Stedile, P.H. Yamazaki, P.C. Gonzalez, \\ A.G. Velasque, M.M. Alievi, C.A.C. Beck
}

Faculdade de Veterinária - UFRGS - Porto Alegre, RS

\begin{abstract}
Corpos estranhos traqueobrônquicos são incomuns em cães e raros em gatos (Brownlie et al., 1986; Dimski, 1991; Pratschke et al., 1999; Zambelli, 2006) e ocorrem devido à aspiração de pequenos objetos por consequência de uma falha no reflexo laríngeo (Lotti, 1992). Animais jovens são mais frequentemente afetados (Fingland, 1996). Objetos maiores tendem a ficar retidos na carina, e pequenos frequentemente chegam aos brônquios e podem causar pneumonia (Uwiera, 1996).
\end{abstract}

Os sinais clínicos surgem de forma aguda e incluem tosse forçada, seca e intermitente. Podem ser observados corrimento nasal purulento ou sanguinolento, engasgo, dispneia, cianose e vômito (Zambelli, 2006). Sibilos podem ser auscultados se o objeto estiver obstruindo parcialmente as vias aéreas (Nelson, 1998). Em oito casos de cães com corpo estranho bronquial foram observadas tosse, halitose, hemoptise em mais da metade dos animais (Dobbie et al., 1986). Os sinais vão depender do tempo de evolução e do tipo de corpo estranho presente.

O diagnóstico pode ser obtido com radiografias, porém, em muitos casos, as radiografias não evidenciam o corpo estranho. O diagnóstico definitivo geralmente é firmado com broncoscopia (Hawkins, 1997). Exsudato bronquial pode ser observado por meio da broncoscopia, sugerindo o local do corpo estranho correlacionando-se com imagens radiográficas de consolidação pulmonar (Nelson, 1998). A ventilação do paciente é um desafio durante a remoção do corpo estranho,

Recebido em 7 de maio de 2011

Aceito em 31 de janeiro de 2012

E-mail: aline.gouvea@bol.com.br independentemente da técnica escolhida. Em alguns casos, uma segunda endoscopia é necessária para confirmação da suspeita de corpo estranho, em razão da presença de exsudato ou hemorragia (Dobbie et al., 1986).

A broncoscopia é usada para remoção de corpos estranhos presentes nas vias aéreas (Johnson, 2001), e, em casos de objetos não recuperáveis devido ao formato, tamanho e localização, indica-se a abordagem cirúrgica, por meio da toracotomia e abertura traqueal (Nelson, 1998; Brownlie et al., 1986; Pacchiana et al., 2001). Não se recomenda a remoção por endoscopia em casos de objetos grandes ou pontiagudos com riscos de perfuração das vias aéreas, de fragmentos vegetais que provocam lesões irreversíveis aos pulmões, e que necessitam de ressecção pulmonar, e quando existe limitação devido ao tamanho do paciente, principalmente em gatos e cães de pequeno porte (Pacchiana et al., 2001). Para esses autores, a broncoscopia pode ser dificultada pela presença de exsudato e hemorragia nas vias aéreas e pelos movimentos cardíacos e respiratórios.

O objetivo deste trabalho foi relatar um caso de corpo estranho traqueal em um cão, da raça Poodle, 2,2kg, três meses de idade, atendido em Hospital Veterinário Escola, com histórico de tosse, engasgos, ânsia de vômito e dispneia, que surgiram de forma aguda. Ao exame clínico, o paciente apresentava sibilos acompanhados de tosse seca. Os demais sinais clínicos encontravam-se dentro da normalidade.

Radiografias torácicas foram realizadas e não demonstraram qualquer alteração. $\mathrm{O}$ diagnóstico 
definitivo foi obtido mediante broncoscopia, por meio de um endoscópio rígido de $4 \mathrm{~mm}$, com o paciente sob anestesia geral. $\mathrm{Na}$ traqueia, observou-se (Fig. 1) a presença de um corpo estranho. Tentou-se a remoção por meio de uma pinça endoscópica, porém não houve sucesso com a manobra em razão do tamanho e localização do corpo estranho e da dificuldade de apreensão. Além disso, o paciente apresentou cianose durante $\mathrm{o}$ procedimento devido à obstrução quase completa das vias aéreas.

Optou-se pelo procedimento cirúrgico de toracotomia e traqueotomia para remoção do corpo estranho. O cão, após pré-oxigenação, recebeu meperidina, $3 \mathrm{mg} \cdot \mathrm{kg}^{-1}$, e sulfato de atropina, $0,044 \mathrm{mg} \cdot \mathrm{kg}^{-1}$, pela via intramuscular, como medicação pré-anestésica. Em seguida, a indução foi realizada com propofol, $3 \mathrm{mg} \cdot \mathrm{kg}^{-1}$, e a manutenção anestésica com isoflurano.

Com o paciente em decúbito lateral esquerdo, o acesso ocorreu no sexto espaço intercostal. A traqueotomia foi próxima à região da carina, e com uma pinça de dissecção delicada, removeuse o corpo estranho (Fig. 2). A anastomose traqueal foi efetuada com pontos interrompidos simples com mononáilon 4-0 circundando os anéis traqueais. Após a sutura traqueal, foi realizada a lavagem da cavidade torácica com solução fisiológica, seguida pelo fechamento do tórax com a técnica habitual.

No pós-operatório, o cão recebeu, por via oral, amoxicilina com clavulanato de potássio, $15 \mathrm{mg} \cdot \mathrm{kg}^{-1}$, a cada 12 horas, durante sete dias, meloxicam, 0,1mg. $\mathrm{kg}^{-1}$, a cada 24 horas, durante três dias, e cloridrato de tramadol, $3 \mathrm{mg} \cdot \mathrm{kg}^{-1}$, a cada oito horas, durante três dias, por via intramuscular. O paciente permaneceu internado durante três dias e recuperou-se satisfatoriamente. Manifestou esporádicos episódios de tosse seca durante a primeira semana de pós-operatório.

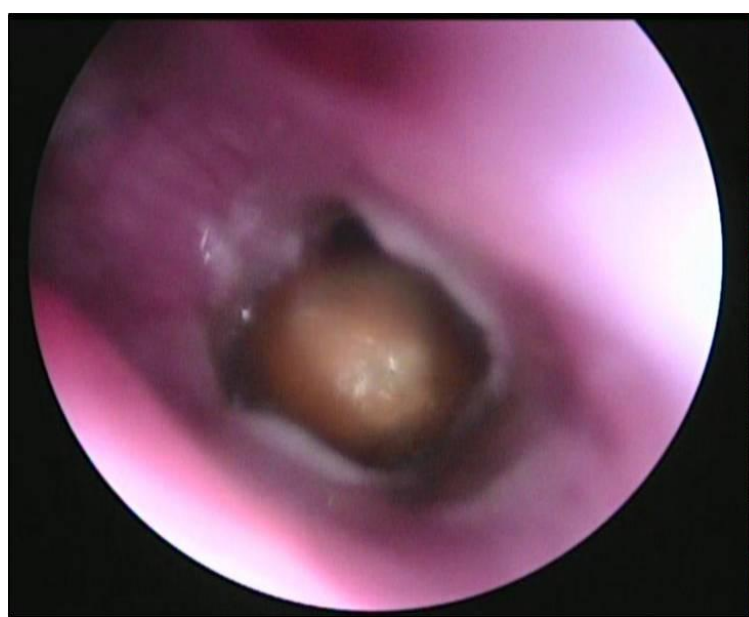

Figura 1. Cão. Observação de corpo estranho traqueal (milho de pipoca) por meio da broncoscopia (esquerda).

Segundo Fingland (1996), a incidência de corpos estranhos é maior em cães jovens, como no caso descrito, possivelmente por seu temperamento curioso. Sinais agudos de alterações respiratórias, como dispneia e tosse intensa, são frequentes em casos de corpos estranhos traqueobrônquicos e devem ser incluídos no diagnóstico diferencial, segundo McGlennon et al. (1986) e Nelson (1998). Na literatura, existem relatos de evolução dos sinais clínicos de até 17 meses (Dobbie et al., 1986). Nesses casos

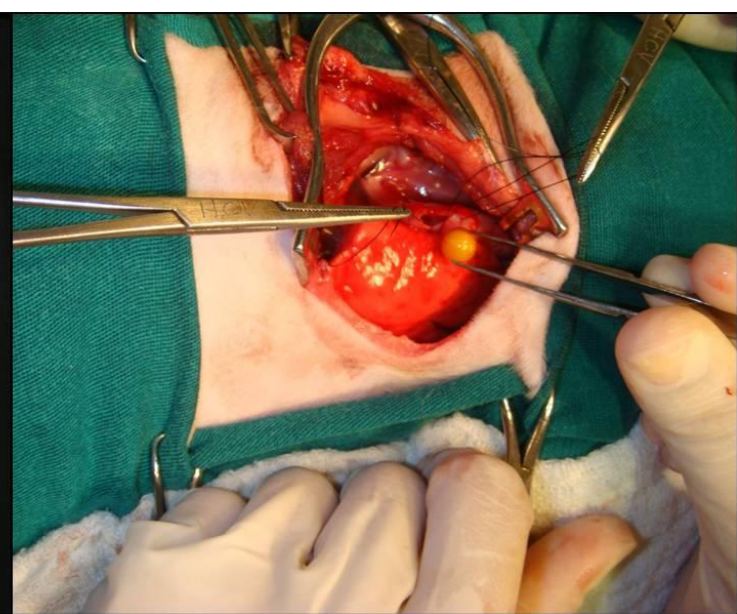

Figura 2. Cão. Remoção do corpo estranho traqueal por meio de toracotomia e traqueotomia (direita).

crônicos, a intensidade da tosse diminui e surgem sinais sistêmicos, como febre, anorexia e prostração, pois ocorre a formação de abscessos pulmonares ou pleurite difusa em razão de migração e desintegração em pequenos fragmentos (Lotti, 1992) ou irritação e toxicidade local (Nelson, 1998), tornando o diagnóstico mais difícil.

Dependendo do tamanho e formato, o corpo estranho pode ser aspirado até os brônquios 
(Fingland, 1996). No presente caso, o objeto era relativamente grande, promovendo obstrução quase completa da passagem de ar. A presença do corpo estranho na traqueia não provocou reação inflamatória, pois o diagnóstico foi precoce, e o objeto encontrado, milho de pipoca, não favoreceu irritação local.

Em caso de objetos radioluscentes, além do exame radiográfico, é necessária endoscopia para confirmação do diagnóstico (McGlennon et al., 1986; Dimski, 1991), como ocorreu neste caso. Em cães e gatos, os corpos estranhos são variados, prevalecendo fragmentos de vegetação (Dobbie et al., 1986; Lotti, 1992). Neste relato, houve aspiração de milho de pipoca, comum em crianças (Kalyanappagol et al., 2007) e não descrito em pequenos animais.

A endoscopia é um importante instrumento para o diagnóstico e a remoção de corpos estranhos, e é considerado o método de escolha na maioria dos casos (Dimski, 1991), pois é menos invasivo e a recuperação do paciente é mais rápida. No presente relato, o porte do paciente, o formato e o tamanho do corpo estranho geraram dificuldade de apreensão do objeto. Além disso, os movimentos respiratórios dificultaram a manobra, conforme citaram Pacchiana et al. (2001). Esses foram os motivos da abordagem cirúrgica por toracotomia.

Pelo fato de não terem sido observadas inflamação ou consolidação pulmonar, fatores que indicam a necessidade de lobectomia, optouse pela traqueotomia na região da carina, local do corpo estranho previamente observado na broncoscopia.

O acesso no sexto espaço intercostal foi efetivo para remoção do milho de pipoca retido na traqueia do paciente. Complicações pósoperatórias significativas não foram observadas, devido ao precoce diagnóstico, sem a evolução de qualquer processo inflamatório das vias aéreas.

Palavras-chave: cão, traqueotomia, broncoscopia

\begin{abstract}
The occurrence of a tracheal foreign body in a three-month-old male Poodle referred to a Teaching Veterinary Hospital due to acute coughing, gagging and nausea is reported. A bronchoscopy under general anesthesia was performed in order to obtain a diagnose. During the bronchoscopy a foreign body (maize popcorn) was observed in the intrathoracic trachea. The surgeon attempted to remove it by endoscopy, but no success was achieved. Therefore, an open procedure was performed and the foreign body removed. The patient progressed satisfactorily after the thoracotomy.
\end{abstract}

Keywords: dog, thoracotomy, bronchoscopy

\section{REFERÊNCIAS}

BROWNLIE, S.E.; DAVIES, J.V.; JONES, D.G.C. Bronchial foreign bodies in four dogs. J. Small Anim. Pract., v.27, p.239-245, 1986.

DIMSKY, D.S. Tracheal obstruction caused by tree needles in a cat. J. Am. Vet. Med. Assoc., v.199, p.477478, 1991.

DOBBIE, G.R.; DARKE, P.G.G.; HEAD, K.W. Intrabronchial foreign bodies in dogs. J. Small Anim. Pract., v.27, p.227-238, 1986.

FINGLAND, R.B. Traqueia e brônquios. In: BOJRAB, M.J. Mecanismos da Moléstia na Cirurgia dos Pequenos Animais, 2.ed. 1996, cap.65, p.452-453.
HAWKINS, E.C. Afecções do sistema respiratório inferior. In: ETTINGER, S.J., FELDMAN, E.C. Tratado de Medicina Interna Veterinária, 4.ed., 1997, v.1, cap.89, p.1094-1095.

JOHNSON, L. Small animal bronchoscopy. Vet. Clin. N. Am.: Small Anim. Pract., v.31, p.691-705, 2001.

KALYANAPPAGOL, V.T.; KULKARNI, N.H.; BRIDI, L.H. Management of tracheobronchial foreign body aspirations in paediatric age group - a 10 year retrospective analysis. Indian J. Anaesth., v.51, p.2023, 2007.

LOTTI, U. Tracheobronchial foreign bodies of plant origin in 153 hunting dogs. Compend. Contin. Educ. Pract. Vet., v.14, p.900-911, 1992.

McGLENNON, N.J.; PLATT, D.; DUNN, J.K. et al., Tracheal foreign body in a cat: a case report. J. Small Anim. Pract., v.27, p.457-461, 1986. 
NELSON, A.W. In: SLATTER, D. Manual de Cirurgia de Pequenos Animais, 2.ed., 1998. v.1, cap.53, p.942-946.

PACCHIANA, P.D.; BURNSIDE, P.K.; WILKENS, B.E. et al. Primary bronchotomy for removal of an intrabronchial foreign body in a dog. J. Am. Anim. Hosp. Assoc., v.37, p.582-585, 2001.

PRATSCHKE, K.M.; HUGHES, J.M.L.; GUERIN, S.R. et al. Foley cathter technique for removal of a tracheal foreign body in a cat. Vet. Rec., v.144, p.181$182,1999$.
UWIERA, R.R.E. Identification and removal of a cereal ear bronchial foreign body. Canine Pract., v.21, p.30-32, 1996.

ZAMBELLI, A.B. Pneumomediastinum, pneumothorax and pneumoretroperitoneum following endoscopic retrieval of a tracheal foreign body from a cat. $J$. $S$. Afr. Vet. Assoc., v.77, p.45-50, 2006. 